\title{
Near-IR Emitting Si Nanocrystals Fabricated by Thermal Annealing of $\mathrm{SiN}_{\mathrm{x}} / \mathrm{Si}_{3} \mathrm{~N}_{4}$ Multilayers
}

\author{
D. M. Zhigunov 1,*(D), A. A. Popov ${ }^{2}$, Yu. M. Chesnokov ${ }^{3}$ (D, A. L. Vasiliev ${ }^{3,4}$, A. M. Lebedev ${ }^{3}$,
} I. A. Subbotin ${ }^{3}$, S. N. Yakunin ${ }^{3}$, O. A. Shalygina ${ }^{5}$ and I. A. Kamenskikh ${ }^{5}$

1 Center for Photonics and Quantum Materials, Skolkovo Institute of Science and Technology, Bolshoy Boulevard 30, bld. 1, 121205 Moscow, Russia

2 Valiev Institute of Physics and Technology, Russian Academy of Sciences, Yaroslavl Branch, Universitetskaya 21, 150007 Yaroslavl, Russia; imiraslab4@yandex.ru

3 National Research Centre "Kurchatov Institute", pl. Akademika Kurchatova 1, 123182 Moscow, Russia; chessyura@yandex.ru (Y.M.C.); a.vasiliev56@gmail.com (A.L.V.); lebedev.alex.m@gmail.com (A.M.L.); i.a.subbotin@gmail.com (I.A.S.); s.n.yakunin@gmail.com (S.N.Y.)

4 Moscow Institute of Physics and Technology (State University), MIPT, Institutskiy per. 9, Dolgoprudny, 141701 Moscow Region, Russia

5 Faculty of Physics, M. V. Lomonosov Moscow State University, Leninskie Gory 1, 119991 Moscow, Russia; olga@vega.phys.msu.ru (O.A.S.); ikamenskikh@bk.ru (I.A.K.)

* Correspondence: d.zhigunov@skoltech.ru

Received: 1 October 2019; Accepted: 2 November 2019; Published: 6 November 2019

\begin{abstract}
Silicon nanocrystals in silicon nitride matrix are fabricated by thermal annealing of $\mathrm{SiN}_{\mathrm{x}} / \mathrm{Si}_{3} \mathrm{~N}_{4}$ multilayered thin films, and characterized by transmission electron microscopy, $\mathrm{X}$-ray reflectivity and diffraction analysis, photoluminescence and X-ray photoelectron spectroscopy techniques. Si nanocrystals with a mean size of about $4 \mathrm{~nm}$ are obtained, and their properties are studied as a function of $\mathrm{SiN}_{\mathrm{x}}$ layer thickness (1.6-2 nm) and annealing temperature (900-1250 $\left.{ }^{\circ} \mathrm{C}\right)$. The effect of coalescence of adjacent nanocrystals throughout the $\mathrm{Si}_{3} \mathrm{~N}_{4}$ barrier layers is observed, which results in formation of distinct ellipsoidal-shaped nanocrystals. Complete intermixing of multilayered film accompanied by an increase of nanocrystal mean size for annealing temperature as high as $1250{ }^{\circ} \mathrm{C}$ is shown. Near-IR photoluminescence with the peak at around 1.3-1.4 eV is detected and associated with quantum confined excitons in Si nanocrystals: Photoluminescence maximum is red shifted upon an increase of nanocrystal mean size, while the measured decay time is of order of microsecond. The position of photoluminescence peak as compared to the one for Si nanocrystals in $\mathrm{SiO}_{2}$ matrix is discussed.
\end{abstract}

Keywords: nanocrystals; silicon; superlattice; photoluminescence; X-ray diffraction; HRTEM; EFTEM; XPS

\section{Introduction}

Following the early studies on porous silicon photoluminescence (PL) [1], optical properties of silicon nanocrystals ( $\mathrm{Si}$ NCs) in solid matrices have been a focus of thorough research. Bright luminescence at room temperature from Si NCs, not observable for bulk silicon, appears very intriguing from the point of view of optoelectronic applications [2]. Different host matrices for Si NCs such as silicon oxide, nitride, and carbide are examined [3-5], while the most intense luminescence is typically observed for $\mathrm{Si}$ NCs in $\mathrm{SiO}_{2}$ matrix due to the smallest concentration of PL quenching centers [6]. At the same time, enhanced electron transport properties of Si NCs array in matrices with lower band gap (silicon nitride or carbide) are preferable for the photovoltaic applications [4]. To achieve a precise control of the size of Si NCs multilayered thin films can be fabricated using so-called superlattice 
(SL) approach [7-9]. This approach allows one to limit the maximum size of Si NCs by deposition of Si-rich layers, wherein Si NCs are self-organized during high temperature annealing, alternating with stoichiometric barrier layers, which should remain unchanged $[9,10]$. However, as shown recently, the stability of multilayers against annealing depends on the thickness of layers and treatment temperature, thus partial or total intermixing of layered structure may occur, and Si NCs with the size exceeding the thickness of initial of Si-rich layers may be formed [11,12].

The question about the origin of observed luminescence is especially complicated in the case of silicon nitride-based superlattices, since a large number of radiative defects are found in $\mathrm{SiN}_{\mathrm{x}}$ films, such as $N_{4}{ }^{+}, N_{2}{ }^{0}$ or K-centers [6,13]. PL maximum attributed to $\mathrm{Si} \mathrm{NCs}$ in $\mathrm{Si}_{3} \mathrm{~N}_{4}$ matrix is detected in a broad range of photon energies, generally from 1.5 to $3 \mathrm{eV}[4,9,13-15]$. One of the main arguments in favor of quantum confinement effect, which is responsible for such PL, is a blue shift of peak energy with decreasing Si NCs size. At the same time, similar PL spectra are observed for $\mathrm{SiN}_{\mathrm{x}}$ films without $\mathrm{Si} \mathrm{NCs}$, whereas corresponding PL peak might be shifted in a wide range from about 1.6 to $2.6 \mathrm{eV}$ by changing $\mathrm{Si} / \mathrm{N}$ ratio $[16,17]$. A characteristic lifetime of such defect-related PL is of order of nanoseconds [18], while Si NC-related PL is known to possess much longer decay times in a microsecond range [3,12]. Hence, time-resolved PL measurements are important for the correct identification of PL source, which are often not presented in papers dedicated to Si NC luminescence in $\mathrm{Si}_{3} \mathrm{~N}_{4}[9,10,13]$.

In the present study we demonstrate the formation of silicon nitride-embedded Si NCs, which emit in near-IR region (peak at 1.3-1.4 eV) with a characteristic PL lifetime in a microsecond timescale. In this spectral region, no contribution from radiative defects is expected. Similar near-IR luminescence with the peaks in the range 1.4-1.7 eV was shown recently from annealed B-doped $\mathrm{SiN}_{\mathrm{x}} / \mathrm{Si}_{3} \mathrm{~N}_{4}$ multilayer films with Si quantum dots produced by magnetron sputtering; however, no time-resolved PL data were provided [10].

\section{Materials and Methods}

\subsection{Sample Fabrication}

Silicon nitride films $\mathrm{SiN}_{\mathrm{x}}$ with different $x$ values were deposited by low frequency $(55 \mathrm{kHz})$ discharge plasma enhanced chemical vapor deposition (LF PECVD). Monosilane $\mathrm{SiH}_{4}$ and ammonia $\mathrm{NH}_{3}$ were used as components of gas mixture. Gas flow ratio $k=\left[\mathrm{NH}_{3}\right] /\left[\mathrm{SiH}_{4}\right]$ defined the stoichiometry coefficient $x$ in deposited $\mathrm{SiN}_{\mathrm{x}}$ materials. Gas mixture with $k=5$ and 1.2 were used for deposition of nearly stoichiometric $\mathrm{Si}_{3} \mathrm{~N}_{4}$ barriers and silicon rich $\mathrm{SiN}_{\mathrm{x}}$ layers $(x \approx 0.85)$, respectively [19]. In total, 18 pairs of layers were deposited on substrates at a power density of $0.2 \mathrm{~W} / \mathrm{cm}^{2}$. Pressure of gas mixture in plasma-chemical reactor was $250 \mathrm{~Pa}$, and the deposition temperature was $380^{\circ} \mathrm{C}$. For the fabricated samples the thicknesses of $\mathrm{SiN}_{\mathrm{x}} / \mathrm{Si}_{3} \mathrm{~N}_{4}$ bilayers are equal to 2/2.25 $\pm 0.2 \mathrm{~nm}$ (SN1) and 1.6/1.75 $\pm 0.2 \mathrm{~nm}$ (SN2), as measured by means of transmission electron microscopy (TEM). Prepared samples were subsequently annealed in a tube furnace under nitrogen atmosphere during $1 \mathrm{~h}$ at the following temperatures $\left(\mathrm{T}_{\mathrm{ann}}\right)$ : 900,1150 and $1250{ }^{\circ} \mathrm{C}$, in order to form Si nanocrystals during phase separation of silicon-rich $\mathrm{SiN}_{\mathrm{x}}$ layers:

$$
y \operatorname{SiN}_{\mathrm{x}}=(y-x) \mathrm{Si}+x \operatorname{SiN}_{\mathrm{y}}
$$

where $y$ is supposed to be close to stoichiometric 1.33 value [20].

\subsection{Sample Characterization}

The cross-section specimens for TEM were studied in a Titan 80-300 TEM/STEM (FEI, USA) at an accelerating voltage of $300 \mathrm{kV}$. The energy filtered TEM (EFTEM) measurements were performed in the low loss region of the electron energy loss spectrum with a $2 \mathrm{eV}$ energy slit around the bulk Si plasmon loss peak $(16.7 \mathrm{eV})$, which is commonly used to visualize a sample superlattice structure. High-resolution TEM (HRTEM) images showing individual Si nanocrystals were obtained at Scherzer defocus value. Phase separation of $\mathrm{SiN}_{\mathrm{x}}$ was studied by X-ray photoelectron spectroscopy (XPS) performed on the 
ESCA branch of the NanoPES station at the Kurchatov synchrotron radiation source (National Research Center Kurchatov Institute) with $\mathrm{Al} K_{\alpha}$ excitation (1486.61 eV). Sample surface sputtering was carried out by the $1.5-\mathrm{keV} \mathrm{Ar}^{+}$ions bombardment in order to remove organic contaminations and native oxide. To study superlattice structure stability against thermal annealing, angular dependences of the intensity of X-ray reflectivity (XRR) were measured in step mode $2 \theta / \omega$ on X-ray diffractometer with a rotating anode (Rigaku SmartLab, Japan) using the characteristic $\mathrm{Cu} K_{\alpha} 1$ line (radiation energy $8.048 \mathrm{keV})$. In-plane grazing incidence X-ray diffraction (XRD) studies were conducted on BM25B beamline at the European Synchrotron Radiation Facility (ESRF) using $22.025 \mathrm{keV}$ radiation energy (incidence angle $\left.0.1^{\circ}\right)$. Photoluminescence (PL) was excited by a He-Cd laser ( $h v_{\mathrm{exc}}=3.81 \mathrm{eV}, 20 \mathrm{~mW}$ power) focused into a spot with $1 \mathrm{~mm}$ diameter. The PL signal was measured using a $500 \mathrm{~mm}$ focal length spectrometer (SOLAR MS 350, Belarus) equipped with a CCD camera with a sensitivity range of 200-1100 nm. The spectra were taken at room temperature and corrected for the system response, as well as for spectrometer dispersion by multiplying by $\lambda^{2}$. For time-resolved PL measurements pulsed $\mathrm{Nd}$ :YAG laser excitation ( $h v_{\mathrm{exc}}=2.33 \mathrm{eV}$, pulse duration $34 \mathrm{ps}$, laser pulse fluence $\sim 3 \mathrm{~mJ} / \mathrm{cm}^{2}$, repetition rate $10 \mathrm{~Hz}$ ) was used. The PL signal was collected by means of intensified CCD (PI-MAX Gen III, Princeton Instruments) coupled to a $500 \mathrm{~mm}$ focal length imaging spectrograph (Princeton Instruments SpectraPro 2500i, USA). All PL spectra were detected within $1 \mu$ s gate width taking various delays after excitation pulse onset in the range from 0 to $40 \mu \mathrm{s}$. The PL decays for different emission energy (1.5 and $2 \mathrm{eV}$ ) are plotted using the PL intensity at a chosen photon energy values as a function of delay time.

\section{Results and Discussion}

\subsection{TEM Results}

Figure 1 shows HRTEM and EFTEM images of SN1 and SN2 films annealed at $\mathrm{T}_{\text {ann }}=1150{ }^{\circ} \mathrm{C}$. Silicon nanocrystals can be seen as sets of lattice fringes (circled) in HRTEM images for both samples (see Figure 1a,d). Bright regions in EFTEM images (see Figure 1b,e) correspond to Si, while the dark ones correspond to $\mathrm{Si}_{3} \mathrm{~N}_{4}$, thus multilayered structure is also seen. At the same time, it is obvious, that size of $\mathrm{Si}$ NCs is not precisely restricted to $\mathrm{SiN}_{\mathrm{x}}$ layer thickness. An effect of coalescence of neighboring nanocrystals throughout $\mathrm{Si}_{3} \mathrm{~N}_{4}$ barrier layers can be observed, thus their shape starts to be non-spherical (see Figure 1a,d). The mean diameter of Si NCs, which is defined as half sum of ellipse major axes in case of non-spherical particles, was estimated from HRTEM images. According to the statistical observations for more than 100 nanocrystals, their most frequently detected mean diameter was $2 \mathrm{~nm}$, as shown in Figure 1c,f, which correlates well with $\operatorname{SiN}_{\mathrm{x}}$ layer thickness (2 and $1.6 \mathrm{~nm}$ ). At the same time, coalescent ellipsoidal-shaped nanocrystals with the mean diameter up to 10 and $9 \mathrm{~nm}$ were formed in case of SN1 and SN2 samples, respectively. Hence, the overall mean size of Si NCs was calculated to be $3.8 \pm 2.3 \mathrm{~nm}$ for SN1 and $3.4 \pm 1.7 \mathrm{~nm}$ for SN2 sample, which reflects the reduction of $\mathrm{SiN}_{\mathrm{x}}$ layer thickness for the latter sample. Formation of nanocrystals with a non-spherical shape was also observed for annealed $\mathrm{SiN}_{\mathrm{x}}$ monolayered films [21], while similar effect of uncontrollable growth of $\mathrm{Si}$ NCs has been demonstrated recently for annealed $\mathrm{SiN}_{\mathrm{x}} / \mathrm{SiO}_{2}$ hetero-superlattices [12]. 

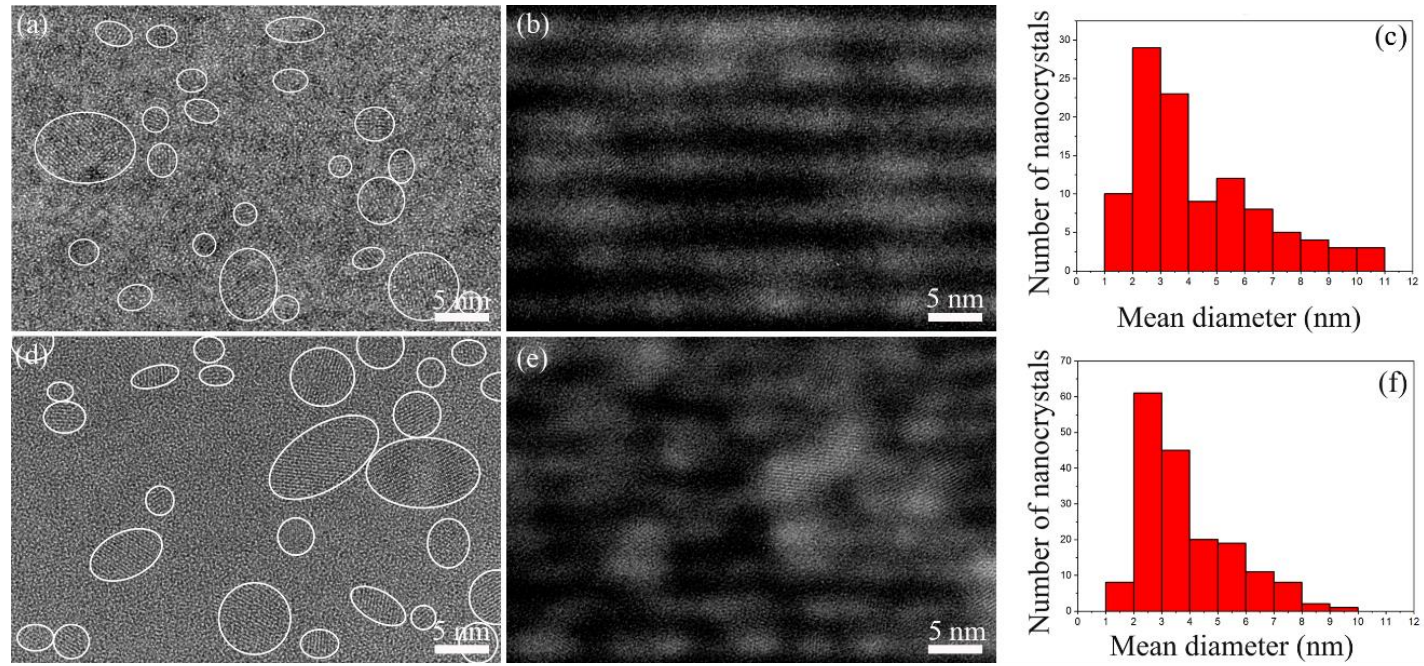

Figure 1. (a) HRTEM image, (b) EFTEM image, and (c) size distribution of $\mathrm{Si}$ NCs for $\mathrm{SiN}_{\mathrm{x}} / \mathrm{Si}_{3} \mathrm{~N}_{4}$ $(2 / 2.25 \mathrm{~nm})$ SN1 sample; (d) HRTEM image, (e) EFTEM image, and (f) size distribution of Si NCs for $\mathrm{SiN}_{\mathrm{x}} / \mathrm{Si}_{3} \mathrm{~N}_{4}(1.6 / 1.75 \mathrm{~nm}) \mathrm{SN} 2$ sample.

\subsection{X-ray Studies}

As results from XRR measurements show in Figure 2, our samples annealed at $1150{ }^{\circ} \mathrm{C}$ may be considered as still multilayered films with some point distortions. Indeed, pronounced Bragg peaks (at around 1.1 and 1.5 degree for SN1 and SN2 sample, respectively) indicate the presence of superlattices, whose periods are estimated as $3.9 \mathrm{~nm}$ (SN1) and $3.1 \mathrm{~nm}$ (SN2), which matches well those obtained by TEM measurements ( 4.25 and $3.35 \mathrm{~nm}$, respectively). At the same time, relatively large width of Bragg peaks also points out at the multilayered structure imperfections, which are most likely coalescent nanocrystals. In turn, an increase of annealing temperature up to $1250{ }^{\circ} \mathrm{C}$ resulted in destruction of SL structure, as evident from Bragg peaks disappearing for both SN1 and SN2 samples (see Figure 2). Such a temperature-dependent SL structure breakdown was observed in our previous study of $\mathrm{SiO}_{\mathrm{x}} / \mathrm{SiO}_{2}$ and $\mathrm{SiO}_{\mathrm{x}} \mathrm{N}_{\mathrm{y}} / \mathrm{SiO}_{2}$ multilayered films with $1.5 \mathrm{~nm}$ thick Si-rich layers, and explained by the gain in the Gibbs free energy for a mixed system as compared with initial unmixed one [11]. At the same time, it is worth noting that similar $\mathrm{SiN}_{\mathrm{x}} / \mathrm{Si}_{3} \mathrm{~N}_{4}$ multilayered structures even with ultrathin $(1 \mathrm{~nm}) \mathrm{Si}_{3} \mathrm{~N}_{4}$ barriers remain stable after high temperature treatment as demonstrated recently $[9,10]$. Hence, we can assume that the most probable reason for the effect of Si NC coalescence demonstrated in Figure 1 is the small enough thickness of $\mathrm{SiN}_{\mathrm{x}}$ layers $(1.6-2 \mathrm{~nm})$, leading to an appearance of distinct intermixing regions. This trend is in full agreement with our previous observations of SL structure intermixing for $\mathrm{SiO}_{\mathrm{x}}$ and $\mathrm{SiN}_{\mathrm{x}}$-based multilayers with ultrathin Si-rich layers $[11,22,23]$.

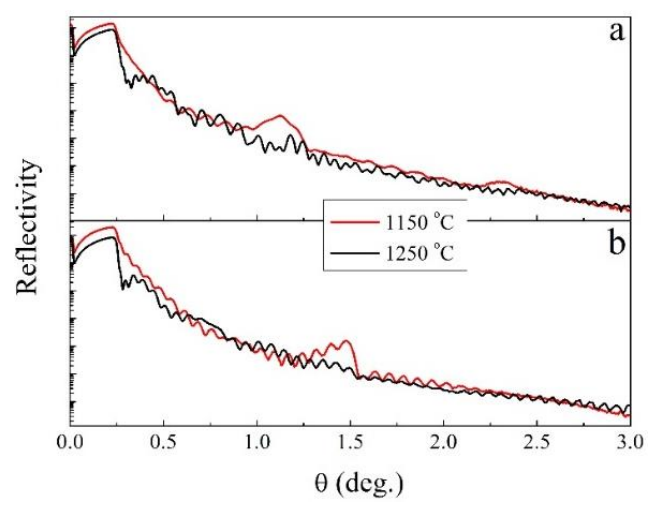

Figure 2. XRR scans for (a) SN1 and (b) SN2 samples annealed at different temperatures. 
The formation of Si NC with an increase of annealing temperature was additionally studied by means of XRD and XPS techniques. XRD scans of SN2 sample are shown in Figure 3. As can be seen, $900{ }^{\circ} \mathrm{C}$ annealing temperature is obviously not enough to form nanocrystals, since XRD pattern constitute of a broad band around the position of $\mathrm{Si}$ (111) diffraction peak, which is a signature of amorphous silicon nanoclusters. In contrast, for higher annealing temperatures relatively narrow peak is observed, which is a typical XRD pattern for Si NCs [9]. Remarkably, the peak becomes narrower with the rise of annealing temperature from $1150{ }^{\circ} \mathrm{C}$ to $1250{ }^{\circ} \mathrm{C}$, consequently the mean size of Si NCs increases by about 30\% according to the estimation by means of Scherrer equation (the same trend is reproduced for SN1 sample). This fact is consistent with SL structure breakdown at $1250{ }^{\circ} \mathrm{C}$ demonstrated by XRR, hence the formation of Si NCs with a larger mean size can be expected, in a similar way as demonstrated previously in case of $\mathrm{SiO}_{\mathrm{x}} \mathrm{N}_{\mathrm{y}} / \mathrm{SiO}_{2} \mathrm{SL}$ annealed at the same temperature [24]. The mean size of $\mathrm{Si}$ NCs grows together with the thickness of $\mathrm{SiN}_{\mathrm{x}}$ layers: As results from comparative XRD measurements (see inset in Figure 3), on the average Si NCs in SN1 sample are about $14 \%$ larger than those in SN2 sample $(4.1 \pm 0.1 \mathrm{~nm}$ vs. $3.6 \pm 0.1 \mathrm{~nm})$, according to calculations using Scherrer equation [9], which agrees well with the mean size estimations performed by analyzing HRTEM images.

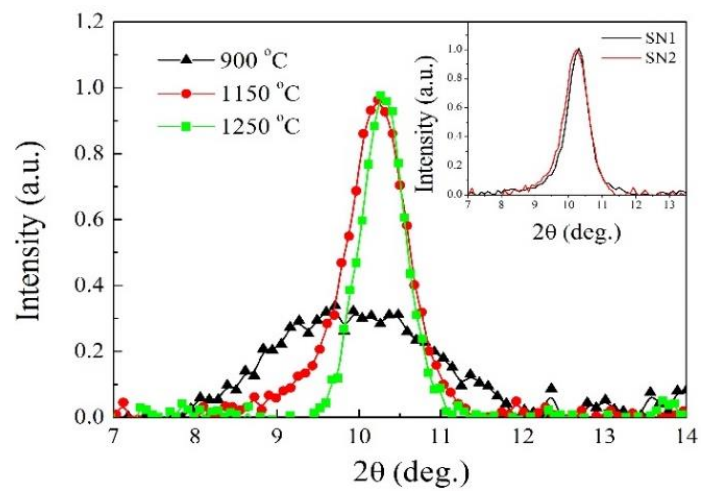

Figure 3. XRD scans around the position of Si (111) diffraction peak ( $10.3^{\circ}$ for photon energy used) for SN2 sample annealed at different remperatures. Inset: XRD scans of SN1 and SN2 samples annealed at $1150{ }^{\circ} \mathrm{C}$.

XPS spectra of SN1 sample before and after annealing at the characteristic energy of Si 2p core levels are presented in Figure 4. The formation of Si nanoclusters $\left(\mathrm{T}_{\mathrm{ann}}=900^{\circ} \mathrm{C}\right)$ and $\mathrm{Si} \mathrm{NCs}\left(\mathrm{T}_{\mathrm{ann}}=1150{ }^{\circ} \mathrm{C}\right)$ can be attributed to an appearance of a shoulder at $99.7 \mathrm{eV}$, which corresponds to $\mathrm{Si}-\mathrm{Si}$ bonds $\left(\mathrm{Si}^{0}\right.$ peak). In turn, evidence of a significant phase separation within $\mathrm{SiN}_{\mathrm{x}}$ layers at $\mathrm{T}_{\mathrm{ann}}=1150^{\circ} \mathrm{C}$ follows out of an appearance of $\mathrm{Si}^{4+}$ peak with a characteristic energy $101.7 \mathrm{eV}$, which corresponds to Si-N bonds in $\mathrm{Si}_{3} \mathrm{~N}_{4}$ matrix [25].

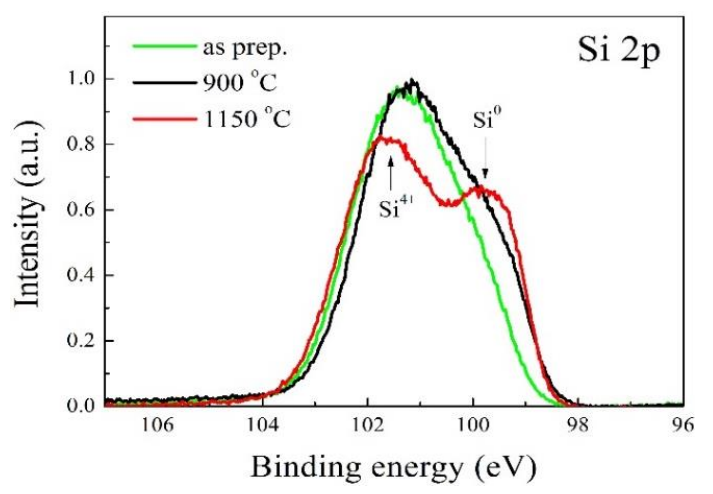

Figure 4. XPS spectra of SN1 sample (as prepared and annealed at different temperatures) measured in the energy region of Si $2 p$ levels. 


\subsection{Photoluminescence Measurements}

PL spectra of SN1 and SN2 samples annealed at $1150{ }^{\circ} \mathrm{C}$ are shown in Figure 5a. An observed PL peak shift may be associated with the size-dependent quantum confinement effect for excitons in $\mathrm{Si}$ NCs. Spectra are characterized by maxima in the near IR range $(885-940 \mathrm{~nm})$, which is not typical for Si $\mathrm{NCs}$ in $\mathrm{Si}_{3} \mathrm{~N}_{4}$ matrix, as mentioned above. Nevertheless, luminescence in this spectral region was also observed recently from similar $\mathrm{SiN}_{\mathrm{x}} / \mathrm{Si}_{3} \mathrm{~N}_{4}$ SLs with Si NCs, but produced by different methods $[10,23]$. Moreover, bare theory of quantum confinement predicts the reduction of an energy gap (i.e., red shift) for Si nanocrystals with the decrease of confinement barriers, i.e., when nanocrystals are incorporated into $\mathrm{Si}_{3} \mathrm{~N}_{4}$ matrix instead of $\mathrm{SiO}_{2}$ [4]. Thus, $\mathrm{PL}$ with lower peak energies from $\mathrm{Si}$ NCs in silicon nitride as compared with silicon oxide matrix $(\sim 1.7 \mathrm{eV}$ at most $)$ is indeed justified. At the same time, the majority of experimental data on $\mathrm{Si} \mathrm{NC}$ luminescence in $\mathrm{Si}_{3} \mathrm{~N}_{4}$ reveals the PL maximum at relatively high photon energies (above 1.6-1.7 eV), which is blue-shifted as compared to a typical emission of $\mathrm{Si}$ $\mathrm{NCs}$ in $\mathrm{SiO}_{2}$ characterized by a maximum at about 1.2-1.7 eV [2,26]. From the theoretical point of view, this discrepancy is usually solved by empirical modification of the theoretical parameters to achieve a better fit with the experimental data [4]. On the other hand, in silicon rich nitrides there are numerous matrix-related radiative defects having strong emission lines, which makes it difficult to distinguish the contribution of Si NCs, especially when short-wavelength excitation is used [13,15]. With respect to SL structures, matrix-related luminescence signal intensity may be reduced by decreasing the thickness of $\mathrm{Si}_{3} \mathrm{~N}_{4}$ barriers, as demonstrated recently by an example of $\mathrm{SiO}_{\mathrm{x}} \mathrm{N}_{\mathrm{y}} / \mathrm{Si}_{3} \mathrm{~N}_{4}$ hetero-SLs [6]. Indeed, in general, luminescence from $\mathrm{Si}$ NCs in $\mathrm{SiN}_{\mathrm{x}} / \mathrm{Si}_{3} \mathrm{~N}_{4}$ SLs with the peak energy at about $1.7 \mathrm{eV}$ or below is observed, when $\mathrm{Si}_{3} \mathrm{~N}_{4}$ barriers has the thickness under $2 \mathrm{~nm}[9,10,23]$. On the opposite, in case of thicker barriers or $\mathrm{SiN}_{\mathrm{x}}$ monolayered films with $\mathrm{Si}$ NCs the position of PL peak is usually found in the spectral range above $1.7 \mathrm{eV}[13,16,27]$. Taking into account a number of radiative defects in $\mathrm{SiN}_{\mathrm{x}}$, which emit at such high photon energies, an attempt to attribute certain PL bands to Si NC emission in $\mathrm{SiN}_{\mathrm{x}}$ seems highly questionable in this case, as emphasized elsewhere [17].
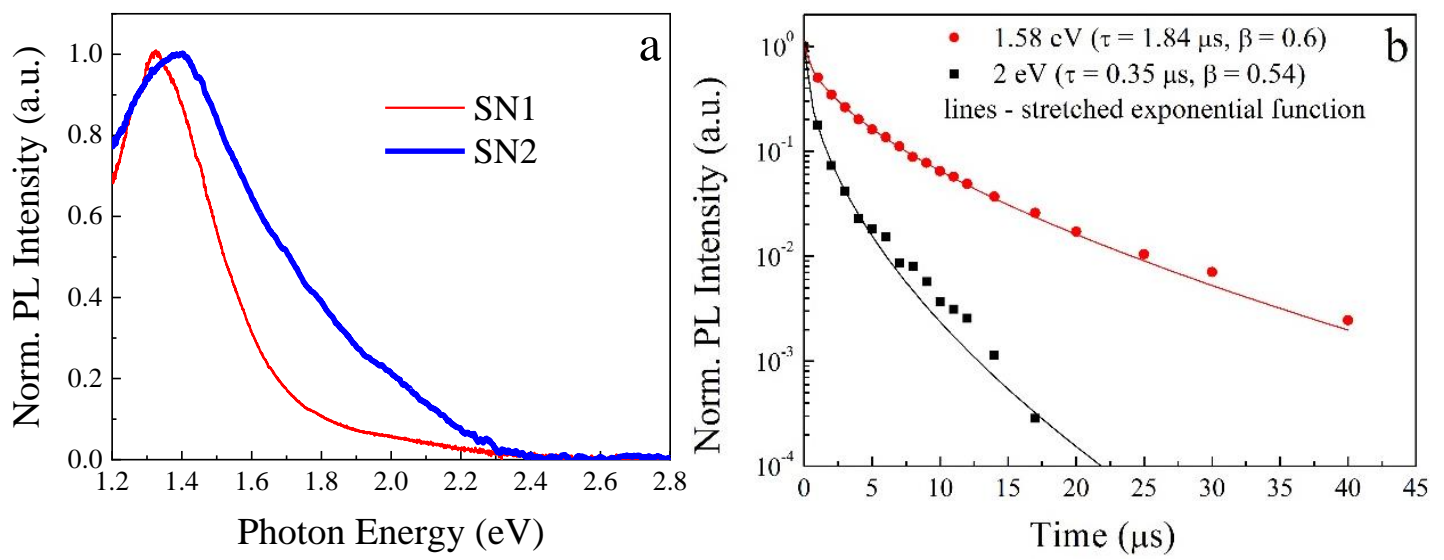

Figure 5. (a) PL spectra of fabricated samples annealed at $1150{ }^{\circ} \mathrm{C}$; (b) PL decay curves for SN1 sample (points) and corresponding approximation using stretched exponential function (lines).

To confirm that exciton recombination in Si NCs is the origin of observed PL for our SL structures, time-resolved PL measurements were carried out. The results for SN1 sample are shown in Figure 5b for two different photon energies. Both curves are characterized by a stretched exponential decay:

$$
I=I_{0} \exp \left[-(t / \tau)^{\beta}\right]
$$

with the time constant $\tau$ reducing from 1.84 to $0.35 \mu$ s upon increase of photon energy. Such reduction as well as relatively long PL lifetime (in a microsecond range) and non-exponential parameter $\beta \sim$ $0.5-0.6$ are typical for quantum confined Si NCs-related PL $[3,28]$. At the same time, characteristic time 
constant seems to be several times smaller than that for $\mathrm{SiO}_{x}$-embedded $\mathrm{Si}$ NCs [3]. The latter may be explained by a more defective nature of $\mathrm{SiN}_{\mathrm{x}}$ matrix as compared to $\mathrm{SiO}_{\mathrm{x}}$ one [6]. Defects like dangling bonds act as luminescence quenching centers, increasing the nonradiative recombination rate and, hence, reducing the measured PL lifetime.

\section{Conclusions}

In the present study, we fabricated $\mathrm{Si} N \mathrm{NC}_{\mathrm{S}}$ in $\mathrm{Si}_{3} \mathrm{~N}_{4}$ matrix by high temperature annealing of $\mathrm{SiN}_{\mathrm{x}} / \mathrm{Si}_{3} \mathrm{~N}_{4}$ multilayered films deposited by low frequency discharge PECVD. Formation of Si NCs is confirmed by HRTEM, EFTEM, XRD and XPS measurements. It is shown that superlattice structure remains stable in general after $1150{ }^{\circ} \mathrm{C}$ annealing with some point distortions such as coalescent nanocrystals. Size of these distinct ellipsoidal-shaped nanocrystals exceeds more than twice the period of multilayered structure. In turn, an increase of annealing temperature up to $1250{ }^{\circ} \mathrm{C}$ led to superlattice breakdown and Si NC mean size growth, in full analogy with the previous observations of the similar effect in $\mathrm{SiO}_{\mathrm{x}} \mathrm{N}_{\mathrm{y}} / \mathrm{SiO}_{2}$ multilayered films annealed under the same conditions. Fabricated samples are characterized by a photoluminescence signal with the peak in near IR range (1.3-1.4 eV), while time-resolved PL measurements allowed us to ascribe this PL to a recombination of quantum confined excitons in Si NCs. In our opinion, the main reason for such low-energy luminescence, which is not typical for $\mathrm{SiN}_{\mathrm{x}}$-embedded $\mathrm{Si} \mathrm{NCs}$, is a negligible contribution from radiative defects in matrix due to small enough thickness of $\mathrm{Si}_{3} \mathrm{~N}_{4}$ barrier layers. Our results are found to agree well with the predictions of quantum confinement theory, which states a redshift of confined energy upon reduction of potential barrier height by changing a wide band gap $\mathrm{SiO}_{2}$ matrix to a lower band gap $\mathrm{Si}_{3} \mathrm{~N}_{4}$.

Author Contributions: Conceptualization, D.M.Z. and I.A.K.; investigation, Y.M.C., A.M.L, I.A.S. and O.A.S.; resources, A.A.P.; writing — original draft preparation, D.M.Z.; writing—review and editing, A.L.V. and A.M.L.; supervision, D.M.Z., S.N.Y. and A.L.V.

Funding: This work was financially supported by the Ministry of Science and Higher Education of the Russian Federation, project No. RFMEFI58117X0026. Silicon nitride film deposition has been performed under the State Program 0066-2019-0003. D.M.Z. gratefully acknowledges the support from the Russian Foundation for Basic Research (grant No. 18-32-20217).

Acknowledgments: We are grateful to Maria Vila Santos at the ESRF for providing assistance in using beamline BM25B. XRR and electron microscopy measurements have been carried out using the equipment of Resource Centers of the X-ray techniques and Probe and Electron Microscopy of NRC "Kurchatov Institute".

Conflicts of Interest: The authors declare no conflict of interest.

\section{References}

1. Kovalev, D.; Heckler, H.; Polisski, G.; Koch, F. Optical Properties of Si Nanocrystals. Phys. Status Solidi B 1999, 215, 871-932. [CrossRef]

2. Takeoka, S.; Fujii, M.; Hayashi, S. Size-dependent photoluminescence from surface-oxidized Si nanocrystals in a weak confinement regime. Phys. Rev. B 2000, 62, 16820-16825. [CrossRef]

3. Linnros, J.; Lalic, N.; Galeckas, A.; Grivickas, V. Analysis of the stretched exponential photoluminescence decay from nanometer-sized silicon crystals in $\mathrm{SiO}_{2}$. J. Appl. Phys. 1999, 86, 6128-6134. [CrossRef]

4. Conibeer, G.; Green, M.; Cho, E.-C.; König, D.; Cho, Y.-H.; Fangsuwannarak, T.; Scardera, G.; Pink, E.; Huang, Y.; Puzzer, T.; et al. Silicon quantum dot nanostructures for tandem photovoltaic cells. Thin Solid Films 2008, 516, 6748-6756. [CrossRef]

5. Wan, Z.; Huang, S.; Green, M.; Conibeer, G. Residual stress study of silicon quantum dot in silicon carbide matrix by Raman measurement. Phys. Status Solidi C 2011, 8, 185-188. [CrossRef]

6. Zelenina, A.; Sarikov, A.; Gutsch, S.; Zakharov, N.; Werner, P.; Reichert, A.; Weiss, C.; Zacharias, M. Formation of size-controlled and luminescent $\mathrm{Si}$ nanocrystals from $\mathrm{SiO}_{\mathrm{x}} \mathrm{N}_{\mathrm{y}} / \mathrm{Si}_{3} \mathrm{~N}_{4}$ hetero-superlattices. J. Appl. Phys. 2015, 117, 175303. [CrossRef] 
7. Heitmann, J.; Kovalev, D.; Schmidt, M.; Yi, L.X.; Scholz, R.; Eichhorn, F.; Zacharias, M. Synthesis and size control of $\mathrm{Si}$ nanocrystals by $\mathrm{SiO} / \mathrm{SiO}_{2}$ superlattices and Er doping. MRS Proc. 2002, 737, F1.6. [CrossRef]

8. Volodin, V.A.; Arzhannikova, S.A.; Gismatulin, A.A.; Kamaev, G.N.; Antonenko, A.K.; Cherkova, S.G.; Cherkov, A.G.; Kochubei, S.A.; Popov, A.A.; Robert, S.; et al. Laser pulse crystallization and optical properties of $\mathrm{Si} / \mathrm{SiO}_{2}$ and $\mathrm{Si} / \mathrm{Si}_{3} \mathrm{~N}_{4}$ multilayer nano-heterostructures. Proc. SPIE 2012, 8700, 870008. [CrossRef]

9. So, Y.-H.; Huang, S.; Conibeer, G.; Green, M.A. Formation and photoluminescence of Si nanocrystals in controlled multilayer structure comprising of Si-rich nitride and ultrathin silicon nitride barrier layers. Thin Solid Films 2011, 519, 5408-5412. [CrossRef]

10. Chen, X.; Yang, W.; Yang, P.; Yuan, J.; Zhao, F.; Hao, J.; Tang, Y. Size-controlled Si quantum dots embedded in B-doped $\mathrm{SiN}_{\mathrm{x}} / \mathrm{Si}_{3} \mathrm{~N}_{4}$ superlatice for Si quantum dot solar cells. J. Mater. Sci. Mater. Electron. 2017, 28, 1322-1327. [CrossRef]

11. Zhigunov, D.M.; Sarikov, A.; Chesnokov, Y.M.; Vasiliev, A.L.; Zakharov, N.; Kashkarov, P.K. Thickness and temperature depending intermixing of $\mathrm{SiO}_{\mathrm{x}} / \mathrm{SiO}_{2}$ and $\mathrm{SiO}_{\mathrm{x}} \mathrm{N}_{\mathrm{y}} / \mathrm{SiO}_{2}$ superlattices: Experimental observation and thermodynamic modeling. Appl. Phys. Lett. 2016, 108, 223102. [CrossRef]

12. Zelenina, A.; Sarikov, A.; Zhigunov, D.M.; Weiss, C.; Zakharov, N.; Werner, P.; López-Conesa, L.; Estradé, S.; Peiró, F.; Dyakov, S.A.; et al. Silicon nanocrystals in $\mathrm{SiN}_{\mathrm{x}} / \mathrm{SiO}_{2}$ hetero-superlattices: The loss of size control after thermal annealing. J. Appl. Phys. 2014, 115, 244304. [CrossRef]

13. Sain, B.; Das, D. Tunable photoluminescence from nc-Si/a-SiN $\mathrm{x}: \mathrm{H}$ quantum dot thin films prepared by ICP-CVD. Phys. Chem. Chem. Phys. 2013, 15, 3881-3888. [CrossRef] [PubMed]

14. Lin, C.-H.; Uen, W.-Y.; Lan, S.-M.; Huang, Y.-C.; Liao, S.-M.; Li, Z.-Y.; Yang, T.-N.; Ku, C.-T.; Chen, M.-C.; Huang, Y.-H. Luminescence mechanisms of silicon-rich nitride films fabricated by atmospheric pressure chemical vapor deposition in $\mathrm{N}_{2}$ and $\mathrm{H}_{2}$ atmospheres. J. Appl. Phys. 2009, 105, 053107. [CrossRef]

15. Wang, M.; Li, D.; Yuan, Z.; Yang, D.; Que, D. Photoluminescence of Si-rich silicon nitride: Defect-related states and silicon nanoclusters. Appl. Phys. Lett. 2007, 90, 131903. [CrossRef]

16. Delachat, F.; Carrada, M.; Ferblantier, G.; Grob, J.-J.; Slaoui, A. Properties of silicon nanoparticles embedded in $\mathrm{SiN}_{\mathrm{X}}$ deposited by microwave-PECVD. Nanotechnology 2009, 20, 415608. [CrossRef] [PubMed]

17. Kistner, J.; Chen, X.; Weng, Y.; Strunk, H.P.; Schubert, M.B.; Werner, J.H. Photoluminescence from silicon nitride-No quantum effect. J. Appl. Phys. 2011, 110, 023520. [CrossRef]

18. Giorgis, F.; Vinegoni, C.; Pavesi, L. Optical absorption and photoluminescence properties of a-Si $i_{1-x} \mathrm{~N}_{x}: \mathrm{H}$ films deposited by plasma-enhanced CVD. Phys. Rev. B 2000, 61, 4693-4698. [CrossRef]

19. Korchagina, T.T.; Marin, D.V.; Volodin, V.A.; Popov, A.A.; Vergnat, M. Structure and optical properties of $\mathrm{SiN}_{\mathrm{x}}: \mathrm{H}$ films with $\mathrm{Si}$ nanoclusters produced by low-frequency plasma-enhanced chemical vapor deposition. Semiconductors 2009, 43, 1514-1520. [CrossRef]

20. Molinari, M.; Rinnert, H.; Vergnat, M. Evolution with the annealing treatments of the photoluminescence mechanisms in a-SiN $\mathrm{S}_{\mathrm{x}}$ : H alloys prepared by reactive evaporation. J. Appl. Phys. 2007, 101, 123532. [CrossRef]

21. Liao, W.; Zeng, X.; Wen, X.; Chen, X.; Wang, W. Annealing and excitation dependent photoluminescence of silicon rich silicon nitride films with silicon quantum dots. Vacuum 2015, 121, 147-151. [CrossRef]

22. Sarikov, A.; Zhigunov, D. Thermodynamic mechanism of the intermixing of multilayered structures in the $\mathrm{SiO}_{x} / \mathrm{SiO}_{2}$ superlattices with nanometer thick layers. Mater. Today Commun. 2017, 13, 163-169. [CrossRef]

23. Zhigunov, D.M.; Martyshov, M.N.; Forsh, P.A.; Kamenskikh, I.A.; Yakunin, S.N.; Kashkarov, P.K. Structure-related current transport and photoluminescence in $\mathrm{SiO}_{\mathrm{x}} \mathrm{N}_{\mathrm{y}}$ and $\mathrm{SiN}_{\mathrm{x}}$ based superlattices with $\mathrm{Si}$ nanocrystals. Phys. Status Solidi A Appl. Mater. 2017, 214, 1700040. [CrossRef]

24. Hartel, A. Structural and Optical Properties of PECVD Grown Silicon Nanocrystals Embedded in $\mathrm{SiO}_{\mathrm{x}} \mathrm{N}_{\mathrm{y}}$ Matrix. Ph.D. Thesis, Albert-Ludwigs-Universität Freiburg im Breisgau, Freiburg, Germany, 5 August 2013.

25. Zhigunov, D.M.; Kamenskikh, I.A.; Lebedev, A.M.; Chumakov, R.G.; Logachev, Y.A.; Yakunin, S.N.; Kashkarov, P.K. X-ray reflectivity and photoelectron spectroscopy of superlattices with silicon nanocrystals. JETP Lett. 2017, 106, 517-521. [CrossRef]

26. Heitmann, J.; Müller, F.; Zacharias, M.; Gösele, U. Silicon nanocrystals: Size matters. Adv. Mater. 2005, 17, 795-803. [CrossRef] 
27. Zelenina, A.; Dyakov, S.A.; Hiller, D.; Gutsch, S.; Trouillet, V.; Bruns, M.; Mirabella, S.; Löper, P.; López-Conesa, L.; López-Vidrier, J.; et al. Structural and optical properties of size controlled Si nanocrystals in $\mathrm{Si}_{3} \mathrm{~N}_{4}$ matrix: The nature of photoluminescence peak shift. J. Appl. Phys. 2013, 114, 184311. [CrossRef]

28. Timoshenko, V.Y.; Lisachenko, M.G.; Shalygina, O.A.; Kamenev, B.V.; Zhigunov, D.M.; Teterukov, S.A.; Kashkarov, P.K.; Heitmann, J.; Schmidt, M.; Zacharias, M. Comparative study of photoluminescence of undoped and erbium-doped size-controlled nanocrystalline $\mathrm{Si} / \mathrm{SiO}_{2}$ multilayered structures. J. Appl. Phys. 2004, 96, 2254-2260. [CrossRef]

(C) 2019 by the authors. Licensee MDPI, Basel, Switzerland. This article is an open access article distributed under the terms and conditions of the Creative Commons Attribution (CC BY) license (http://creativecommons.org/licenses/by/4.0/). 